\title{
Dinâmica das alterações do baço associadas ao estado clínico de cães com leishmaniose visceral*
}

\section{Dynamic of changes of the spleen associated with the clinical status of dogs with visceral leishmaniasis}

\author{
Simone Mousinho Freire, ${ }^{* *}$ Ângela Piauilino Campos, ${ }^{* *}$ Reginalo Roris Cavalcante, ${ }^{* * *}$ José Ângelo Lauletta Lindoso, ${ }^{* * * *}$ \\ Francisco Assis Lima Costa*****
}

\begin{abstract}
Resumo
Foram avaliadas as alterações esplênicas de cães com leishmaniose visceral, sintomáticos e assintomáticos, em relação ao número de sinais clínicos observados nestes animais. Cães sintomáticos foram divididos em cinco grupos de acordo com o número de sinais clínicos presentes. Nos grupos com três ou mais sinais, houve hipertrofia e hiperplasia dos cordões esplênicos e depleção de células linfóides da bainha periarteriolar. No grupo de cães com apenas um sinal clínico houve depleção de folículos da polpa branca. Hiperplasia dos folículos foi observada em intensidade maior no grupo de cães mostrando mais de cinco sinais clínicos. Granulomas estavam presentes em maior intensidade no grupo de cães exibindo cinco sinais. Granulações eosinofílicas no citoplasma de células plasmáticas (corpúsculos de Russell) foram significativamente maiores no grupo de cães com cinco sinais clínicos em comparação com aqueles com apenas um, dois, três e quatro sinais clínicos e cães assintomáticos. Os resultados mostram que o baço apresenta profundas alterações morfológicas que podem influenciar a evolução da infecção.
\end{abstract}

Palavras-chave: Sistema fagocítico mononuclear, cão, Leishmania (L.) infantum sinais clínicos.

\begin{abstract}
Alterations in the spleen of dogs with symptomatic and asymptomatic leishmaniasis have been evaluated with respect to the number of clinical signs observed in such animals. Symptomatic dogs were divided into five groups according to the number of clinical signs presented. In groups with three or more signs, there was hypertrophy and hyperplasia of the splenic cords and depletion of periarteriolar lymphatic sheath cells. In the group of dog with only one clinical sign,a there was follicle depletion in the white pulp. Follicle hyperplasia was higher in the canine group showing more than five clinical signs. Granulomas were present in a greater quantity in the canine group exhibiting five signs. Eosinophil granulations in the cytoplasm of plasma cells (Russell bodies) were significantly greater in the canine group with five clinical manifestations compared to those with only one, two, three and four manifestations and to asymptomatic dogs. The results show that the spleen undergoes profound morphologic changes that can influence the outcome of infection.
\end{abstract}

Keywords: mononuclear phagocystic system , dog, Leishmania (L.) infantum,clinical signs.

\section{Introdução}

A leishmaniose visceral (LV) é uma zoonose causada pela Leishmania (L.) infantum (Mauricio et al., 1999; Shaw, 2007). Nas Américas é transmitida pela picada da fêmea de Lutzomyia longipalpis (Monteiro et al., 2005) e afeta principalmente órgãos do sistema mononuclear fagocitário (Rey, 2008).

O cão tem papel importante no ciclo infeccioso da LV por apresentar parasitismo cutâneo intenso, facilitando a infecção do vetor (Lainson; Shaw, 1987; Molina, 1994). É considerado um bom modelo de estudo da progressão da LV, pois as alterações são semelhantes às observadas em humanos infectados.

As lesões histopatológicas clássicas da leishmaniose visceral canina (LVC) são observadas principalmente em órgãos do sistema fagocítico mononuclear como baço, linfonodos, fígado e medula óssea (Duarte, 2000; Costa et al., 2003; Verçosa et al., 2008; Lima, 2014). O baço desempenha um papel crucial no curso da LV, pois está sempre envolvido na interação parasitohospedeiro (Nylén et al., 2007). Por ser um órgão linfóide secundário, inicia uma resposta a antígenos intravasculares (Abbas; Lichtman, 2003) que contribuem para o estabelecimento do espectro geral dos eventos da LV.

Uma vez que o programa de controle da LVC no Brasil recomenda a eutanásia dos cães sorologicamente positivos, a maioria destes animais podem ser examinados para a avaliação do baço, local onde ocorre replicação intensa e persistente do parasito. Sua distribuição compromete outros órgãos, determinando as diversas manifestações clínicas.

${ }^{*}$ Recebido em 25 de junho de 2013 e aceito em 28 de fevereiro de 2014.

**Discentes do Programa de Pós-graduação em Ciência Animal, Universidade Federal do Piauí, Brasil.

***Departamento de Microbiologia e Parasitologia, Centro de Ciências da Saúde, Universidade Federal do Piauí, Brasil.

****aboratório de Soroepidemiologia e Imunobiologia do Instituto de Medicina Tropical, Universidade de São Paulo, Brasil.

*****Setor de Patologia Animal, Departamento de Clínica e Cirurgia Veterinária, Centro de Ciências Agrárias, Universidade Federal do Piauí, Brasil. Autor para correspondência: Francisco Assis Lima Costa, Setor de Patologia Animal, Centro de Ciências Agrárias, Campus Socopo, S/N, 64049-550, Teresina, Piauí, Brasil. Tel: +55 863215 5760, Fax: +55 863215 5753. E-mail: fassisle@gmail.com. 
Um dos aspectos mais relevantes da identificação de fenótipos de células $\mathrm{B}$ e $\mathrm{T}$ no baço é a oportunidade de compreender que o órgão é uma estrutura imune altamente organizada, variando morfologicamente em resposta a diferentes estímulos (Valli, 1993; de Lima, 2012). O estudo das alterações esplênicas em cães naturalmente infectados com Leishmania (L.) infantum, associado à gravidade das manifestações clínicas, pode mostrar particularidades imunopatológicas capazes de interferir na progressão da infecção e, assim, contribuir para a compreensão da resistência ou suscetibilidade à LVC.

O objetivo deste estudo foi avaliar a intensidade das alterações do baço em diferentes fases de evolução da LVC de modo a compreender a dinâmica das lesões esplênicas e sua relação com as manifestações clínicas e patológicas, bem como fornecer subsídios para a identificação de cães que são suscetíveis e resistentes à doença em áreas endêmicas.

\section{Material e Métodos}

Trinta e seis cães de diferentes idades, raças e sexos, procedentes da Gerência de Zoonoses (GEZOON) da cidade de Teresina, Piauí, foram utilizados. O experimento foi realizado no Setor de Patologia Animal, Departamento de Clínica e Cirurgia Veterinária do Centro de Ciências Agrárias (CCA) da Universidade Federal do Piauí (UFPI). Os procedimentos envolvendo os cães foram realizados de acordo com o Guia Brasileiro de Cuidado e Uso de Animais de Laboratório (Projeto 3.964/97 - http://www.planalto.gov.br). Todos os protocolos experimentais foram previamente aprovados pelo Comitê de Ética da Universidade Federal do Piauí, Brasil.

O diagnóstico de LV foi realizado pelo teste de imunofluorescência indireta (IFI) combinado com cultura em meio Schneider adicionado ao meio NNN (Sigma-Aldrich) e detecção de Leishmania em esfregaço de baço, medula óssea esternal ou linfonodo poplíteo, corados com Giemsa.

Os cães foram divididos clinicamente em dois grupos de acordo com uma classificação modificada por Pozio et al. (1981). O grupo 1 foi composto por 30 cães com teste positivo para Leishmania (L.) infantum e com manifestações clínicas da doença. O grupo 2 foi composto por seis cães com teste positivo para Leishmania (L.) infantum, mas sem manifestações clínicas da doença. Os cães do grupo 1 foram subdivididos em 5 subgrupos, conforme o número de sinais clínicos: subgrupo $A$ (composto por seis cães com um sinal clínico), subgrupo B (seis cães com dois sinais clínicos), subgrupo $C$ (seis cães com três sinais clínicos), subgrupo $D$ (seis cães com quatro sinais clínicos) e subgrupo $E$ (seis cães com cinco ou mais sinais clínicos).

Os cães foram considerados sintomáticos se pelo menos um dos seguintes sinais clínicos estivesse presente: onicogrifose, lesões de pele, perda de peso, linfadenopatia local ou generalizada, diarreia, epistaxe, conjuntivite, anorexia e febre. Cães assintomáticos estavam infectados, mas não mostravam sinais de LV e o diagnóstico foi estabelecido por teste sorológico e parasitológico positivos.

Os cães foram submetidos a uma rigorosa avaliação clínica e coletado material para o diagnóstico de LV. Subsequentemente, foi induzida a anestesia com cetamina (Vetbrands, Brasil), xilazina (Vetbrands, Brasil) e diazepam (Novafarma, Brasil) na dose de $20 \mathrm{mg} / \mathrm{kg}$ de peso vivo. Os cães foram, então, eutanasiados com uma injecção intravenosa ou intracardíaca de solução saturada de cloreto de potássio. A necropsia completa foi realizada imediatamente e colhido fragmentos da região central do baço para realização de imprint, e em seguida esses fragmentos foram fixados em formol tamponado com fosfato, embebidos em parafina e cortados em secções de $5 \mu \mathrm{m}$ de espessura para estudo histopatológico e imunoistoquímico (Mikel, 1994).

Para a classificação das principais lesões esplênicas os seguintes parâmetros foram observados: 1) Congestão, evidenciado pela dilatação do seio esplênico com eritrócitos, separando amplamente centros germinativos e trabéculas, 2) Neutrófilos, evidenciado pela presença de várias células com núcleos segmentados na área imediatamente adjacente ao folículo esplênico e à polpa vermelha, 3) Granuloma, evidenciado pela presença de acumulações focais de macrófagos, algumas células epitelióides, linfócitos e plasmócitos, 4) Hiperplasia folicular, evidenciada pelo aumento do centro germinativo folicular, tanto em tamanho quanto em densidade e acentuação da zona marginal, 5) Depleção de folículo, como evidenciado por uma redução na densidade do centro germinativo, 6) Depleção de células T, como evidenciado por uma redução de células da bainha periarteriolar.

Para citologia, as lâminas com imprint de baço foram fixadas em metanol, coradas com Giemsa (Mikel, 1994) e examinadas por microscopia de luz, com uma ampliação de 100 x para quantificação de amastigotas.

Para histologia, os fragmentos de tecido esplênico foram processados e corados com hematoxilina-eosina (HE) e ácido periódico de Schiff (PAS). Em seguida foi realizada análise por microscopia de luz (Axiolab, Carl Zeiss, Alemanha) para a classificação das lesões e identificação de amastigotas de leishmânias.

Para imunoistoquímica, incubou-se secções de tecido esplênico montados em lâminas, com anticorpo policlonal de camundongo anti-Leishmania amazonensis (Costa et al, 2003) na diluição de 1:1600. A amplificação da reação foi realizada com o sistema estreptavidina-peroxidase (Dako Corporation, Carpinteria EUA código P0397). A revelação foi feita com 0,3 $\mathrm{mg} / \mathrm{ml}$ de 3,3'-diaminobenzidina (Sigma Chemical, EUA) e $0,06 \%$ de peróxido de hidrogénio. A reação foi contracorada com hematoxilina de Harry (Sigma Chemical, EUA).

Os resultados histopatológicos e imunoistoquímicos (determinação da carga parasitária) foram analisados semiquantitativamente. A localização, distribuição e a intensidade das lesões foram medidas numa escala de 0 a 5 , em que $0=$ normal, 1 = mínimo, 2 = média, 3 = moderado, 4 = moderadamente severa, 5 = severa. $\mathrm{Na}$ análise comparativa dos dados, foi utilizado teste estatístico não-paramétrico, utilizando o programa Sigma Stat (Jandel Corporation, San Rafael, CA). O teste de Kruskal-Wallis foi aplicado para comparação múltipla de grupos. Nos casos com diferença significativa, foram utilizados os teste de Student-Newman-Keuls ou de Dunn. O teste de Mann-Whitney foi usado para comparar dois grupos. O nível de significância foi estabelecido em $p<0,05$. 


\section{Resultados}

Todos os cães eram sorológica ou parasitologicamente positivos para LV. Foram detectados parasitas no baço, linfonodo poplíteo, ou em amostras de medula óssea por exame microscópico de esfregaços ou cultura de tecido esplênico.

A presença de anticorpos anti-Leishmania variou de 1:40 a 1:5760 em cães sintomáticos e 1:45 a 1:720 em cães assintomáticos. Os sinais clínicos mais frequentes nos 30 cães estudados foram linfadenopatia $(n=26,86,7 \%)$, lesões de pele $(n=24,80 \%)$, perda de peso $(n=18,60 \%)$, conjuntivite $(n=10$, $33,3 \%)$ e onicogrifose $(n=8,26,7 \%)$.

A análise da carga parasitária revelou que os cães sintomáticos apresentaram maior número de parasitos do que os cães assintomáticos ( $P=0,0253$, teste de Mann-Whitney) (Figura 1A).

A análise histopatológica do baço revelou alterações caracterizadas por infiltração de neutrófilos (Figura 1B), presença de granuloma, hiperplasia folicular e depleção de células $\mathrm{T}$, com maior intensidade conforme se acentuavam as manifestações clínicas. No entanto, a depleção de folículos foi mais intensa em cães com um menor número de sinais clínicos. Outras lesões foram inicialmente manifestadas por congestão e hipercelularidade da polpa vermelha, com presença de linfócitos, macrófagos e neutrófilos e subsequente redução do processo congestivo e número de folículos reativos (Figura $1 \mathrm{C}$ ). Nos grupos com três ou mais sinais clínicos, houve hipertrofia e hiperplasia dos cordões esplênicos.
Na polpa branca, observou-se a depleção dos folículos no grupo de cães mostrando um sinal clínico. Nos grupos com 3, 4 e 5 sinais clínicos houve hiperplasia e depleção de folículos linfóides, presença de numerosas mitoses e depleção de células da bainha periarteriolar (Figura 1D). No entanto, a hiperplasia folicular foi maior no grupo de cães com cinco sinais clínicos em comparação com os grupos com 1 e 2 sinais $(P=0,02$, teste de Kruskal-Wallis e Dunn).

Acúmulos focais de macrófagos, linfócitos e plasmócitos foram observados na polpa vermelha de todos os grupos. No entanto, as alterações aumentavam conforme aumentava a intensidade das manifestações clínicas. Este arranjo celular é típico de reação inflamatória granulomatosa, classificadas neste estudo como granuloma.

Havia, numericamente, mais granulomas nos grupos com dois, três, quatro e cinco sinais clínicos em comparação ao grupo com apenas um sinal clínico e ao grupo assintomático. Esta diferença foi maior no grupo com cinco sinais clínicos em comparação ao grupo com um sinal clínico e ao grupo assintomático $(P=0,003$, teste de Kruskal-Wallis e Dunn). Observou-se que a lesão na polpa vermelha foi caracterizada por hipercelularidade devido à presença de linfócitos, macrófagos e neutrófilos, que era numericamente mais expressiva nos grupo de cães com cinco sinais clínicos em comparação com os grupos com um e dois sinais. A coloração com ácido periódico de Schiff (PAS) revelou a secreção de material proteináceo, sob a forma de grânulos eosinofílicos arredondos (corpúsculos de Russell), por células

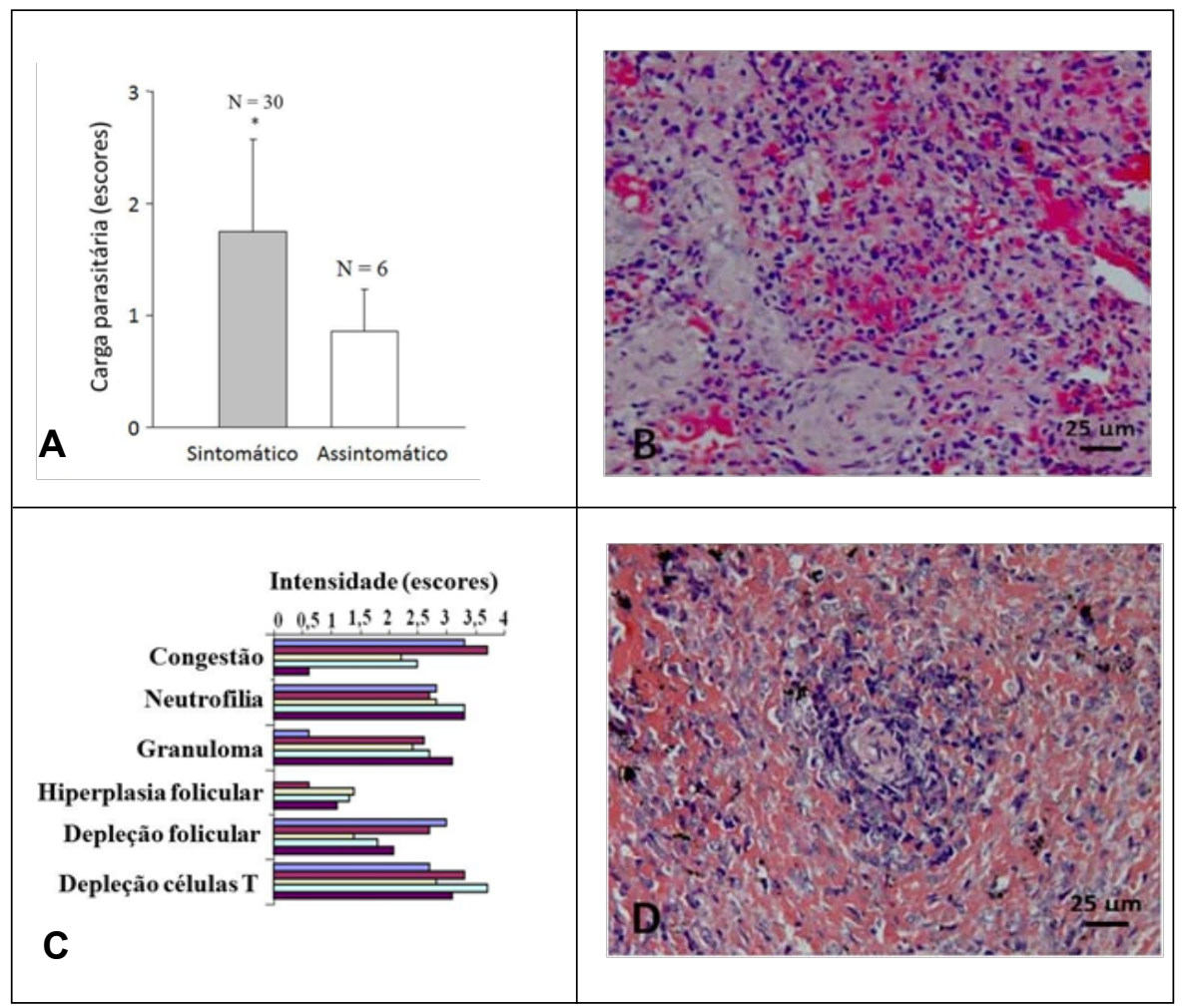

Figura 1: Alterações do baço de cães naturalmente infectados com leishmaniose visceral. (A) Análise semi-quantitativa da carga parasitária por imunoistoquímica (mediana de escores e intervalo entre percentis 25 e 75) em baço de cães sintomáticos e assintomáticos com leishmaniose visceral. $\mathrm{N}$ $=$ número de cães por grupo. * $p=0,0253$ (Teste de Mann-Whitney). (B) Infiltrado de neutrófilos em baço de cão naturalmente infectado por Leishmania (L.) infantum. Coloração: H-E. (C) Alterações no baço e intensidade das manifestações clínicas nos 30 cães sintomáticos com leishmaniose visceral. Em cada padrão de alteração, são observados de 1 a 5 sinais clínicos, da coluna superior para a inferiror. A intensidade das lesões foram medidas numa escala de 0 a 5 , em que $0=$ normal, $1=$ mínimo, $2=$ média, $3=$ moderado, $4=$ moderadamente severa, $5=$ severa. (D) Depleção de células da bainha periarteriolar. Coloração: $\mathrm{H}-\mathrm{E}$ 
foliculares linfóides. As granulações foram mais intensas em cães sintomáticos em comparação com os cães assintomáticos ( $P=0,140$, teste de Mann-Whitney). Entre os cães sintomáticos, a presença de corpúsculos de Russell foi maior no grupo com cinco sinais clínicos, quando comparado com os grupos com um, dois, três e quatro sinais clínicos e grupo assintomático ( $P$ $=0,0002$, teste de Kruskal-Wallis e Dunn).

Amastigotas e antígeno de Leishmania foram observados no citoplasma de macrófagos e livres no tecido esplênico das regiões cortical e medular de 32 (88,8\%) dos 36 cães examinados. Antígeno de Leishmania estava presente em um padrão celular em células fagocitárias da polpa vermelha e como material particulado no tecido intersticial.

\section{Discussão}

Os resultados deste estudo mostraram que as alterações no baço são compartimentalizadas e a morfologia do órgão varia, dependendo do estímulo desencadeado pela Leishmania e seus antígenos.

A análise clínica revelou como alterações mais frequentes: linfadenopatia em 26 cães $(86,7 \%)$, seguido pelas lesões na pele em 24 cães (80\%), perda de peso em 18 cães $(60 \%)$, conjuntivite em 10 cães $(33,3 \%)$ e onicogrifose em 12 cães $(26,7 \%)$. Estas manifestações podem aumentar em número com o aumento na gravidade das alterações morfológicas no baço. Em geral, ocorre uma grande variedade de alterações, contribuindo para determinar o espectro geral de eventos da LV (Ferrer, 1999; Lima, 2014).

Com as análises citológica e histopatológica foi difícil visualizar amastigotas. A carga parasitária foi melhor avaliada por imunoistoquímica. A imunoistoquímica é realmente uma técnica altamente sensível e específica, quando comparada com o exame usando lâminas coradas com HE (Kenner et al., 1999).

No presente estudo não foi observada uma relação entre a presença de granuloma e uma redução dos sinais clínicos. Estudos com camundongos BALB/c infectados com Leishmania donovani mostraram que a formação de granulomas é órgão específica (Murray, 2001) e nem sempre se correlaciona com o controle da infecção (Lemos et al., 2000), como foi observado nesse estudo. Com a progressão da doença o baço apresentou alterações estruturais que conduziram à formação de granulomas, que não tinha qualquer papel de proteção. Cabe ressaltar que o controle da infecção por reação granulomatosa é dependente da secreção de citocinas por células inflamatórias, principalmente interferon- $\gamma$ e interleucina-2 na leishmaniose experimental (Murray et al., 1992). Ao contrário, carga parasitária elevada tem sido observada, mesmo na presença de elevada expressão de interferon-y, sugerindo que níveis elevados de interferon-y no baço de cães infectados por L. Infantum, não resultam na eliminação completa do parasita (Strauss-Ayalia et al., 2007).

A presença de infiltração de neutrófilos nos grupos de cães sintomáticos e assintomáticos chamou a atenção. A presença de células polimorfonucleares na lesão causada pela LV permanece em grande parte desconhecida. No entanto, no baço de camundongos BALB/c infectados com Leishmania infantum, os neutrófilos parecem exercer algum papel no controle da carga parasitária (Rousseau et al., 2001). Com efeito, a presença de neutrófilos foi maior nos cães sintomáticos que tiveram uma maior carga parasitária que os cães assintomáticos. Estes dados sugerem que o parasita tem algum papel sobre a ação dos neutrófilos, semelhante ao que ocorre nos macrófagos onde a presença da leishmânia os protege da morte por apoptose. (Moore; Matlashewski, 1994;Nicolato, 2013).

Alterações esplênicas foram mais severas em grupos de animais que apresentaram mais sinais clínicos. Assim, mesmo sem conhecer a duração da infecção, é provável que o grupo de animais que apresentaram apenas um sinal clínico estivesse na fase inicial da doença, porque as manifestações clínicas da LVC progridem com o aumento da carga parasitária (Lage et al., 2007). Depleção dos folículos no grupo que mostrou somente um sinal clínico, provavelmente resultou da interação inicial do parasita com a zona marginal do folículo linfóide (Abbas; Lichtman, 2003).

Exacerbação da resposta imune humoral ocorre em animais susceptíveis, com hiperplasia folicular e produção de anticorpos específicos e não específicos contra o parasita e seus antígenos (Abranches et al., 1991). Depleção do folículo não foi observado no início da infecção de hamsters experimentalmente infectados com Leishmania (L.) chagasi. No entanto, a hiperplasia folicular e folículos com pouca atividade foram vistos na infecção tardia (Corbett et al., 1992). Esses resultados apresentam similaridade com o que foi observado neste estudo. Embora as espécies sejam diferentes, a infecção é causada pelo mesmo agente patogênico.

Depleção de células da bainha periarteriolar era evidente em todos os cães sintomáticos, refletindo uma maior predisposição desses cães para o desenvolvimento de LV. Embora os cães assintomáticos sejam capazes de controlar o aparecimento de lesões e doença clínica (Killick-Kendrick et al., 1994, Pinelli et al., 1994), cerca de 15 a 18\% podem evoluir para a manifestação da doença (Alvar et al., 2004). Uma mudança no estado de saúde do cão, decorrente da administração de imunossupressores ou uma doença imunossupressora grave, pode levar à ativação da infecção latente e o desenvolvimento dos sinais clínicos. Além disso, tem sido sugerido que uma predisposição genética para a susceptibilidade e resistência à LVC possa ocorrer (Baneth et al., 2008). Dois genes têm sido implicados na susceptibilidade a LVC: o alelo DLA (antígeno de leucócito de cão)-RB1*01502 de cães no Brasil (Quinnell et al, 2003) e os haplótipos do gene canino Slc11a1 na Espanha (Altet et al., 2002).

A presença de grânulos proteicos eosinofílicos no citoplasma de linfócitos constitui anticorpos secretados por células plasmáticas (corpúsculos de Russell) (Majno; Joris, 1996). A presença de numerosas granulações no grupo de cães com cinco sinais clínicos e a progressiva diminuição dessas granulações nos grupos com quatro, três, dois e um sinal clínico e o grupo assintomático, mostrou que a secreção de imunoglobulina in situ está associada a manifestação clínica da doença. Ao contrário, os níveis circulantes de anticorpos não mostrou nenhuma relação com o estágio clínico da doença, como tem sido observado em outros estudos (OMS, 1990).

Embora não tenha sido o foco principal deste estudo, sugerese que algumas alterações estruturais que ocorrem no baço no curso da LV, podem ser avaliadas por meio de biópsia esplênica. Este método é realizado atualmente apenas para fins de deteção de parasitos. Material de biópsia permite a realização 
de exames citológicos, histopatológicos e imunocitoquímicos. Estes testes podem identificar componentes celulares e moleculares importantes para a compreensão das alterações imunopatológicas que ocorrem no baço com a progressão da LVC.

As alterações mais graves observadas em cães sintomáticos, por exemplo, congestão, presença de neutrófilos, formação de granulomas, hiperplasia e hipertrofia dos cordões esplênicos e hipercelularidade da polpa vermelha, determinaram a esplenomegalia. Essas alterações apresentaram alguma relação com a maior susceptibilidade à infecção canina. Estudos realizados por nosso grupo enfatizaram que o xenodiagnóstico de cães sintomáticos foi positivo quando linfadenopatia e/ ou esplenomegalia estavam presentes. Estas condições foram provavelmente relacionadas a níveis mais elevados de parasitemia que facilitaram a transmissão ao vetor (Verçosa et al., 2008). O volume do baço é um parâmetro simples e fácil de mensurar, sem necessidade de testes sofisticados adicionais. Apesar de sua pouca utilização em exame clínico de rotina, este parâmetro pode contribuir para a identificação de animais que são potencialmente susceptíveis e resistentes à infecção por Leishmania.

\section{Referências}

ABBAS, A.K.; LICHTMAN, A.H. Cells and tisues of the immune system. In: MALLEY, J.; KREHLING, H. (eds.) Cellular and molecular immunology. 5 ed. Philadelphia: Saunders, 2003, p.16-39.

ABRANCHES, P.; PEREIRA, M.C.D.S.; SILVA, F.C.; GOMES, G.M.S.; JANS, J.G. Canine leishmaniasis: pathological and ecological factors influencing transmission of infection. Journal of Parasitology, v.77, p.561-577, 1991.

ALTET, L.; FRANCINO, O.; SOLANO-GALLEGO, L.; RENIER, C.; SÁNCHEZ, A. Mapping and sequencing of the canine NRAMP1 gene and identification of mutations in leishmaniasis-susceptible dogs. Infection and Immunity,v.70, p. 2763-2771, 2002.

ALVAR, J.; CANAVATE, C.; MOLINA, R.; MORENO, J.; NIETO, J. Canine leishmaniasis. Advances in Parasitology,v.1, p.1-88, 2004.

BANETH, G.; KOUTINAS, A.F.; SOLANO-GALLEGO, L.; BOURDEAU, P.; FERRER, L. Canine leishmaniosis - new concepts and insights on an expanding zoonosis: part one. Trends in Parasitology,v.24, p.324-330, 2008.

CORBETT, C.E.; PAES, P.P.; LAURENTI, R.A.; ANDRADE JR, M.D.; DUARTE, M.I.S. Histopathology of lymphoid organs in experimental leishmaniasis. International Journal of Experimental Pathology,v.73, p.417-433, 1992.

COSTA, F.A.L.; GOTO, H.; SALDANHA, L.C.B.; SILVA, S.M.M.S.; SINHORINI, I.L.; SILVA, T.C.; GUERRA, J.L.Histopathologic Patterns of Nephropathy in Naturally Acquired Canine Visceral Leishmaniasis. VeterinaryPathology,v.40, p.677-684, 2003.

DE LIMA, V.M;, FATTORI, K.R.; DE SOUZA, F.; EUGENIO, F.R.; DOS SANTOS, P.S.; ROZZA,D.B.;MACHADO,D.F. Apoptosis in T lymphocytes from spleen tissue and peripheral blood of L. (L.) chagasi naturally infected dogs. Veterinary Parasitology 184: 147-153,2012.

DUARTE, M.I.S.Patologia das principais doenças tropicais no Brasil. Leishmaniose visceral (calazar). In: BRASILEIRO, F.G. Bogliolo (ed)Patologia. 6 ed. Rio de Janeiro: Guanabara Koogan, 2000, p.1215-1275.
No baço, o estímulo antigênico por Leishmania causa a ativação de células residentes que migraram recentemente para o órgão. Dependendo do perfil genético e imunológico do animal, profundas alterações morfológicas ocorrem acompanhadas por uma resposta mista Th1 e Th2 (Strauss-Ayalia et al., 2007). O controle da replicação do parasita, a progressão da doença ou a cura são determinados pelo equilíbrio entre estes dois padrões dicotômicos. Citocinas e quimiocinas têm uma participação decisiva nesse controle (Baneth et al., 2008).

É interessante observar que poucos estudos já foram realizados sobre o envolvimento imunopatogênico do baço de cães naturalmente infectados por Leishmania (L.) infantum. Esta parece ser a primeira abordagem ao estudo da dinâmica das alterações do baço associadas com a progressão da doença, mensurada pelo número de sinais clínicos presentes nos cães.

Os resultados deste estudo mostraram que o baço apresenta acentuadas alterações morfológicas relacionadas à progressão da LV. Em cães com deficiência imunológica, essas alterações podem determinar a doença clínica. Estudos adicionais utilizando biópsias de baço, associados a resultados de análises citológicas e histológicas podem ser úteis para avaliar o perfil imunológico de resistência e susceptibilidade à LVC.

FERRER, L.M. Clinical aspects of canine leishmaniasis: an update.Proceedings of the International Canine Leishmaniasis Forum, Barcelona Spain,1999, p. 6-10.

KENNER, J.R.; ARONSON, N.E.; BRATTHAUER, G.L.; TURNICKY, R.P.; JACKSON, J.E.; TANG, D.B.; SAL, P. Immunohistochemistry to identify Leishmania parasites in fixed tissues. Journal of Cutaneous Pathology, v.3, p.130-136,1999.

KILLICK-KENDRICK, R.;KILLICK-KENDRICK, M.;PINELLI, E.;DEL REAL, G.;MOLINA, R.;VITUTIA, M.M.;CAÑAVATE, M.C.;NIETO, J. A laboratory model of canine leishmaniasis: the inoculation of dogs with Leishmania infantum promastigotes from midguts of experimentally infected phlebotomine sandflies. Parasite,v.1, p.311-318, 1994.

LAGE, R.S.; OLIVEIRA, G.C.; BUZEK, S.C.U.; GUERRA, L.L.; GIUNCHETTI, R.C.; CORREA-OLIVEIRA, R.; REIS, A.B. Analysis of the cytokine profile in spleen cells from dogs naturally infected by Leishmania chagasi. Veterinary Immunology and Immunopathology, v.115, p.135-145, 2007.

LAINSON, R.; SHAW, J.J. Evolution, classification and geographical distribution. In: PETERS, W.; KILLICK-KENDRICK, R.(eds.) The Leishmaniasis in Biology and Medicine. London, UK: Academic Press, 1987, p.1-120.

LEMOS, S.V.; ASCENSÃO, J.S.; SAMPAIO, P.T.V.; FREITAS, L.A.R. DiferentLeishmania species determine distinct profiles of immune and histopatogical response in CBA mice. Microbes and Infection, v.15, p.1807-1815, 2000.

LIMA, I. S.; SILVA J. S.; ALMEIDA, V. A. JUNIOR, F. G. L.; SOUZA, P. A. N.; LARANJEIRA, D.F.; MOURA-NETO, J.P.; FRAGA,D.B.M.; FREITAS, L.A.R.; DOS-SANTOS, W.L.C. Severe Clinical Presentation of Visceral Leishmaniasis in Naturally Infected Dogs with Disruption of the Splenic White Pulp. PLOS ONE.v.9 (2),2014.

MAJNO, G.; JORIS, I. Cells, tissues, and disease: principle of general pathology. United States of America: Blackwell Science, 1996, p. 123-173.

MAURICIO, I.L.; HOWARD, M.K.; STOTHARD, J.R.; MILES, M.A. Genetic diversity in the Leishmania donvani complex. Parasitology, v.119, p.237-246, 1999. 
MIKEL, U.V. Advanced laboratory methods in histology and pathology. American Registry of Pathology Washington DC, 1994.

MOLINA R, AMELA C, NIETO J, SAN-ANDRES M, GONZALEZ $F$, et al. Infectivity of dogs naturally infected with Leishmania infantum to colonized Phlebotomus perniciosus. Trans $R$ Soc Trop Med Hyg 88: 491-493,1994.

MONTEIRO, E.M.; SILVA, J.C.F.; COSTA, R.T.; COSTA, D.C.; BARATA, R.A.; PAULA, E.V.; COELHO, G.L.L.M.; ROCHA, M.F.; DIAS, C.L.F.; DIAS, E.D. Leishmaniose visceral: estudo de flebotomíneos e infecção canina em Montes Carlos, Minas Gerais. Revista da Sociedade Brasileira de Medicina Tropical, v.38, p.147-152,2005.

MOORE, K.J.; MATLASHEWSKI,G. Intracellular infection by Leishmania donovani in hibits macrophage apoptosis. The Journal of Immunology, v.152, p. 2930-2937,1994.

MURRAY, H.W.; SQUIRES, K.E.; MIRALLES, C.D.; STOECKLE, M.Y.; GRANGER, A.M.; GRANELLI-PIPERNO, A.; BOGDAN,C. Acquired resistance and granuloma formation in experimental visceral leishmaniasis. Differential T-cell and lymphokine roles in initial versus established immunity. The Journal of Immunology, v.148, p.1858-1863, 1992.

MURRAY, H.W. Tissue granuloma structure-function in experimental visceral leishmaniasis. International Journal of Experimental Pathology, v. 82, p. 249-267,2001.

NICOLATO, R. C.; ABREU, R.T.; ROATT ,B.M.; AGUIARSOARES, R.D.O.; REIS, L.E.S. CARVALHO, M.G.; CARNEIRO,C.M.; GIUNCHETTI,R.C.; BOUILLET, L.E.M.; LEMOS,D.S.; COURA-VITAL,W.; REIS, A.B. Clinical Forms of Canine Visceral Leishmaniasis in Naturally Leishmania infantumInfected Dogs and Related Myelogram and Hemogram Changes. PLOS ONE, v. 8 (12), 2013.

NYLÉN, S.; MAURYA, R.; EIDSMO, L.; MANANDHAR, K.D.; SUNDAR, S.; SACKS, D. Splenic accumulation of IL-10 mRNA in T cells distinct from CD4+CD25+ (Foxp3) regulatory $T$ cells in human visceral leishmaniasis. The Journal of Experimental Medicine, v. 204, p. 805-817, 2007.

ORGANIZACÍON MUNDIAL DE LA SALUD - OMS. Lucha contra las leishmaniasis. Série de informes técnicos 793. Genebra, 1990.
PINELLI, E.; KILLICK-KENDRICK, R.; WAGENAAR, J.; BERNADINA, W.; DEL REAL, G.; RUITENBERG, J. Cellular and humoral immune reponses in dogs experimentally and naturally infected with Leishmania infantum. Infection and Immunity, v.62, p.229-235,1994.

POZIO, E.; GRANDONI, L.; BETTINI, S.; GRAMICCIA,M. Leishmaniasis in Tuscany (Italy). VI. Canine leishmaniasis in the focus of Monte Argentario (Grosseto). Acta Tropica, v.38, p.383 393,1981 .

QUINNELL, R.J.; KENNEDY, L.J.; BARNES, A.; COURTENAY, O.; DYE, C.; GARCEZ, L.M.;SHAW, M.A.; CARTER, S.D.; THOMSON, W.; OLLIER, W.E.Susceptibility to visceral leishmaniasis in the domestic dog is associated with MHC class II polymorphism. Immunogenetic, v.55, p.23-28, 2003.

REY, L. O complexo "Leishmania donovani” e a leishmaníase visceral. In: REY, L. Parasitologia: Parasitos e doenças parasitárias do homem nas Américas e na África. 4 ed. Rio de Janeiro: Guanabara Koogan, 2008.p. 396-409.

ROUSSEAU, D.; DEMARTINO, S.; FERREA, B.; MICHIELS, J.F.; ANJUĖRE, F.; FRAGAKI, K.; LE FICHOUX,Y. In vivo involvement of polymorpho nuclear neutrophils in Leismania infantum infection. BMC Microbiology, p.1-17, 2001.

SHAW, J.The leishmaniases - survival and expansion in a changing world. A mini-review. Memorias Do Instituto Oswaldo Cruz 102: 541-547,2007

STRAUSS-AYALIA, D.; BANETHA, G.; JAFFEC,C.L. Splenic immune responses during canine visceral leishmaniasis. Veterinary Research, v.38, p. 547-564, 2007.

VALLI, V.E.O.The hematopoietic system. In: JUBB, K.V.F.;KENNEDY, P.C.;PALMER, N. (eds.) Pathology of domestic animals. 5 ed. New York: Academic Press, 1993, p. 262-323.

VERÇOSA, B.L.A.; LEMOS, C.M.; MENDONÇA, I.L.; SILVA, S.M. M.S.; CARVALHO, S.M.; GOTO, H.; COSTA, F.A.L. Transmission potential, skin inflammatory response and parasitism of symptomatic and asymptomatic dogs with visceral leishmaniasis. BMC Veterinary Research, v.4, p.45, 2008. 